The Agriculturists 13(2): 105-112(2015) ISSN 2304-7321 (Online), ISSN 1729-5211 (Print)

\title{
Farmers' Attitude Towards Using Agro-Chemicals in Rice Production: A Case in Laxmipur District of Bangladesh
}

\author{
Shaikh Shamim Hasan ${ }^{1 \& 4}$, Mithun Kumar Ghosh ${ }^{2}$, Md. Shamsul Arefin ${ }^{1}$ and Sabina Sultana ${ }^{3}$ \\ ${ }^{I}$ Dept. of Agricultural Extension and Rural Development, Bangabandhu Sheikh Mujibur Rahman \\ Agricultural University, Gazipur-1706, Bangladesh; ${ }^{2}$ Dept. of Agricultural Extension and Rural \\ Development, Exim-Bank Agricultural University, Chapainawabgonj, Bangladesh; ${ }^{3}$ Dept. of Agriculture \\ Extension (DAE), Gazipur, Bangladesh; ${ }^{4}$ Chinese Academy of Sciences (CAS), Beijing, China \\ *Corresponding author and Email: shinuextn120@yahoo.com
}

Received: 26 October 2015

Accepted: 12 December 2015

\begin{abstract}
The study was conducted to determine the farmers' attitude towards using agro-chemicals in rice field in Laxmipur district of Bangladesh. Data were collected from seventy farmers following simple random sampling technique, complied and interpreted as per objectives of the study. Most of the farmers were middle aged, had primary level of education with small farm size, medium extension media contact with an average family annual income of about 1350 USD. About $87 \%$ of the farmers had low to medium knowledge on use of agro-chemicals in rice cultivation. About $74 \%$ of the farmers had moderately favorable attitude towards using agro-chemicals. Family annual income, extension media contact and knowledge on agro-chemical were the most important factors that affect the attitude of the farmers towards using agro-chemicals in crop production. Therefore it is recommended that arrangement of need based training with more extension contact for the farmers will be helpful to improve the behavior of using agro-chemicals.
\end{abstract}

Keywords: Farmers attitude, agro-chemicals, crop production

\section{Introduction}

Bangladesh is a least developed country (Hasan et al., 2015) of the universe and mostly an agricultural country in which rural area is more than the urban one (Sultana and Hasan, 2010) and where over $80 \%$ population is based in rural areas (Sultana et al., 2010). Although modern agriculture has increased the overall productivity of the country but it yields several ecological problems (Ghosh and Hasan, 2013). A common element of agricultural technology are different types of agrochemicals or pesticides which are commonly utilized throughout the world for controlling diseases, pests and weeds (Damalas and Eleftherohorinos, 2011). The most important benefit of using pesticides are economical, comprising yield and quality of crops and decrease of other inputs like labor and fuel (Damalas, 2009). Moreover, it is seen from the last few decades that different pesticides are used to safe the crops from pest damage and thereby increase the crop production (Delcour et al., 2015).

The issues related to soil fertility is very important for overall integrated plant nutrient management (Hasan et al., 2005a). Hasan et al. (2005b) showed that in Bangladesh, continuation of imbalanced chemical fertilizer use is an 
important cause of crop yield reduction and environmental degradation. There was little use of agro-chemicals in Bangladesh until 1970s and after that there is remarkable rise of use. The pesticide use during 1977 was $0.26 \mathrm{~kg}$ of active ingredients per hectare, which jumped to $1.23 \mathrm{~kg}$ per hectare in 2002. Moreover, pesticide use in crop field flourished a faster rate of $10 \%$ annually (from 1977 to 2009) (Rahman, 2010).

Excessive use of agrochemicals are harmful to environment and health of the people (Hou and $\mathrm{Wu}, 2010$; Pimentel, 2005). According to the World Bank (2006) report, approximately 1-5 million people around the world are suffering from pesticide contamination and over use of it and about 20000 faces death due to this poisoning in the developing countries. This condition is so severe in the developing countries than that in the developed ones (Hou and $\mathrm{Wu}$, 2010). Unlike other countries of the world, Bangladesh experienced a dramatic increase of the pesticide use over the last four decades (Rahman, 2013).

Increase in use of pesticide is mainly due to the extension of modern technologies (Pingali and Rola, 1995), although it is harmful from the farmers' social, health and environmental perspective. Wilson and Tisdell (2001) identified several causes of pesticide use by the farmers of developing countries, which includes poor understanding of the sustainable pesticide use, ignorance of both long and short run pesticide using cost, finding no options of using pesticide and weak regulations of pesticide using law. Although there is shortage of assessment of pesticide use impact on human health, but research from the USA noted 67000 annual cases of pesticide poising (Pimentel, 1995) which accounts for over $\$ 2.5$ billions (Tegtmeier and Duffy, 2004). Using pesticide is also a cause of surface and ground water contamination as well as increase number of resistant pests (Ahmad et al., 2007). Moreover, excess use pesticide in the crop field is helpful to destroy the agroecosystem (Iqbal et al., 1997). Many farmers are not fully aware sometimes or properly informed of the health risks associated with day to day pesticide use (Isin and Yildirim, 2007; Salameh et al., 2004).

It is a common picture of the farmers of mostly developing countries of the world of over using of agrochemicals as they are not well aware of poisoning effect of pesticides and use it without having enough safety measures and try to avoid smaller harvest (Khan, 2011; Rao et al., 2009; Stadlinger et al., 2011).

In view of the above evidence, it is necessary for the farmers of the country to utilize agrochemicals into their fields more judiciously to minimize their health and economic losses. There is a dearth of research of identifying the farmers' view of using agro-chemical in their crop fields. Therefore, the current study was undertaken to: (i) examine the farmers' attitude towards using agro-chemicals in the crop field and (ii) to identify the farmers' important characteristics which influence their attitude towards using agro-chemicals.

\section{Materials and Methods}

\subsection{Research design}

The study applied a descriptive research design. A structured interview schedule was used to collect data from the respondents. The respondents were selected from two villages namely Beghaa and Sonapur of Ramganj Upzila under Laxmipur district. Total number of farmers of the study area was 415 which was the population of the study and all these farmers were cultivating mainly rice. Out of 415 farmers, 70 farmers were selected as sample following simple random sampling technique. The interview schedule consisted of two parts: (a) personal characteristics of the farmers and (b) their attitudes toward use of agro-chemicals. The entire process of data collection was completed from December 2013 to February 2014.

\subsection{Measurement of dependent variables}

Attitude of farmers towards the use of agrochemicals in rice cultivation was considered as 
dependent variable of the study. The respondents were asked to give their attitude regarding 20 statements related to using agro-chemicals in rice cultivation. Among the statements 10 were positive and 10 were negative, arranged simultaneously to help avoid subjects in expressing their opinion. Before the survey, the instrument was checked for content and validity by a panel of experts.

Farmers' attitude was measured by constructing a 5-point Likert type scale ranging from $1=$ strongly disagree and $5=$ strongly agree. Each respondent was asked to express his extent of agreement or disagreement by checking against any of the five agreement types. Salawat et al. (2013), Ghosh and Hasan (2013) and Chouichom and Yamao (2010) also used the same scale in their respective studies. Higher values designated positive attitude towards the use of agrochemicals in rice cultivation.

\subsection{Measurement of independent variables}

The independent variables of this study were farmers' age, educational qualification, family size, total land area, family annual income, extension media contact, training received and knowledge on agro-chemical use.

Age of respondent was measured on the basis of actual length of his life and expressed in years. The education was measured by the number of years of schooling. Family size was measured by the total number of members including the respondent himself, spouse, children and other permanent dependents who lived together as family unit. The total land area possessed by the farmer under farm and homestead was the basis of measuring farm size and which was expressed in hectare here. The family yearly income of the farmers from different sources was the annual income of the farmers and it was expressed in Bangladeshi Taka (BDT) and USD. For measuring extension media contact of the respondent, a four-point scale i.e., not at all, rarely, occasionally and frequently was used and appropriate weights were assigned to quantify the variable. Training received was measured by the total number of days that a respondent had attended training in his/her entire life from different agricultural related organizations and from other organizations under various training programs.

Twenty questions were selected in the interview schedule for measuring farmers' knowledge on use of agro chemicals in their fields. Points assigns for each of the correct answer was 2, partially correct answer was 1 and incorrect answer was 0 . Weight for responses on the 20 questions of a respondent were added together to get his score on knowledge of fertilizers and pesticides. Hasan et al. (2015) also used the same weighing technique when they measured the rural women's agricultural knowledge in Gazipur district of Bangladesh.

Statistical Package for Social Science (SPSS) software was used to perform data analysis and analyses like frequency count, means, ranges with percentages were performed. Multiple regression analysis was administered to identify the factors affecting the farmers' attitude of using agro-chemicals in crop production.

\section{Results and Discussion \\ 3.1. Farmers' characteristics and their attitude towards use of agro-chemicals}

Table 1 represents eight socio-demographic information of the respondents incorporating age, educational qualification, family size, total land area, family annual income, extension media contact, training received and level of knowledge on using agro-chemicals. It is revealed that the respondents were, on an average, about 49 years of old with primary level of education. The literacy of farmers helps improving their communication behavior, as it allows one person to better understand the printed media (Sultana and Hasan, 2010). It is a good picture that no respondent was illiterate in the study area. Hasan et al. (2010) in their study also found the same result regarding no illiteracy. Khan et al. (2015) reported that more educated farmers used less agro-chemicals in their fields. 
The average number of the family members of the respondent farmers was 6.41 (Table 1). Although the average family size of Bangladesh is 4.93 (Anonymous, 2015) which is quite smaller than that of the present study. All the respondents had small land areas of 0.02 to 1.01 hectares. The average annual family income of the farmers was 1,08,000 BDT (1,350 USD). Extension media contact of the respondents ranged from 6 to 15 and the farmers were categorized into three groups according to Hasan et al. (2010). The majority (65.7\%) of the farmers had medium extension media contact. The Knowledge of using agro-chemicals of the farmers ranged from 30 to 38 with the average score was 33.96 . The majority $(54.2 \%)$ of the farmers had medium knowledge of using agrochemicals in their crop fields (Table 1).

Table 2 shows that farmers' attitude towards the use of agro-chemicals in rice cultivation which is the main focus of this study. This attitude scores of the farmers varied from 63 to 85 with average of 79.73 and they are categorized into three classes according to Ghosh and Hasan (2013). The results indicate that most of the farmers had moderately favorable attitude towards using agro-chemicals in their fields for rice production. $17.3 \%$ of the farmers possessed highly favorable attitude towards the use of agro-chemicals in rice cultivation, while a majority $(74.2 \%)$ possessed moderately favorable attitude. Currently more attention is paid on the sustainable farming methods and its impact on environment (Damalas and Eleftherohorinos, 2011; Ronald and Adamchak, 2010). To maintain ecological balance of environment, favorable attitude on the environmental issue of the farmer is necessary. Most of farmers of the study area agreed to the beneficial and harmful effects of agro-chemicals use in rice cultivation. Many of them also possessed similar attitude that use of too much agro-chemicals in rice cultivation could do harm for the earth and its important insects, earthworms and other micro organisms. This is a positive sign of sustainable agriculture and environment management.

\subsection{Farmers' characteristic and their influence on attitude of using agro-chemical}

This section examines the farmers' characteristics which influence their attitude of using agro-chemicals in rice production. Regression results in Table 3 indicate that three variables are statistically significant predictors out of eight variables: 1) farmer's annual income; 2) extension media contact and 3) knowledge on use of agro-chemicals. These variables together explained $46.9 \%$ of the variance of effective factors on respondents' attitude towards using agro-chemicals in rice cultivation. The respondents who retained one or more of these characters at a higher level were found to have a higher level of attitude; hence they could use these chemicals in a more judicious way.

The estimated result of the multiple regression analysis is satisfactory as it fulfils some of the criteria. Firstly, the adjusted $\mathrm{R}^{2}$ (which is the measure of goodness of fit of the estimated regression model) value of 0.439 indicates a good fitting of the model. The model also depicts that $R$ value is $0.685, R^{2}$ value of 0.469 and the F-test shows that the estimated regression is quite relevant which means dependent variable is related to each specified explanatory variables. Secondly, three of the estimated coefficients are statistically significant at the 0.01 level, which is significantly different from zero.

Reports of Ghosh and Hasan (2013) reveled that farmers' annual income had significant effect on the attitude of their sustainable agricultural practices. The individuals who have good knowledge about pesticides risks can easily safe themselves against exposure to pesticide (Arcury et al., 2002; McCauley et al., 2002). Salazar et al. (2004) conducted a study on young farm workers and their vulnerability to pesticide and concluded that perceived vulnerability to pesticide and associated diseases were dependent on their protective behavior and attitude of agricultural works. 
Table 1. Socio-demographic profiles of the respondents $(n=70)$

\begin{tabular}{|c|c|c|c|c|}
\hline Variable & Categories & Frequencies(n) & $\%(\mathrm{n})$ & Average score \\
\hline \multirow{3}{*}{ Age } & Young (up to 35 ) & 2 & 2.8 & \multirow{3}{*}{48.60} \\
\hline & Middle (36-50) & 41 & 58.6 & \\
\hline & Old $(>50)$ & 27 & 38.6 & \\
\hline \multirow{3}{*}{$\begin{array}{l}\text { Educational } \\
\text { qualification }\end{array}$} & Illiterate & 0 & 0 & \multirow{3}{*}{5.87} \\
\hline & 1 to 5 years of schooling & 44 & 62.9 & \\
\hline & 6 to 10 years of schooling & 26 & 37.1 & \\
\hline \multirow[t]{3}{*}{ Family size } & Small (1-3) & 0 & 0 & \multirow{3}{*}{6.41} \\
\hline & Medium (4-6) & 39 & 55.7 & \\
\hline & Large $(>6)$ & 31 & 44.3 & \\
\hline \multirow[t]{3}{*}{ Total land area } & Small (0.02-1.01 ha) & 70 & 100 & \multirow{3}{*}{0.46} \\
\hline & Medium (1.01-3.03 ha) & 0 & 0 & \\
\hline & Large (>3.03 ha) & 0 & 0 & \\
\hline \multirow{3}{*}{$\begin{array}{l}\text { Family annual } \\
\text { income }\end{array}$} & Up to 55000 BDT (687.5 USD) & 0 & 0 & \multirow{3}{*}{$\begin{array}{l}108000.60 \\
(1350.01 \mathrm{USD})\end{array}$} \\
\hline & $\begin{array}{l}55001-110000 \text { BDT (687.51- } \\
1375 \text { USD) }\end{array}$ & 41 & 58.6 & \\
\hline & $>110000 \mathrm{BDT}(>1375 \mathrm{USD})$ & 29 & 41.4 & \\
\hline \multirow{3}{*}{$\begin{array}{l}\text { Extension media } \\
\text { contact }\end{array}$} & Low (up to 6) & 4 & 5.7 & \multirow{3}{*}{9.21} \\
\hline & Medium (7-10) & 46 & 65.7 & \\
\hline & High $(>10)$ & 20 & 28.6 & \\
\hline \multirow[t]{2}{*}{ Training received } & No training & 39 & 55.7 & \\
\hline & Training & 31 & 44.3 & \\
\hline \multirow{3}{*}{$\begin{array}{l}\text { Knowledge on } \\
\text { agro-chemical use }\end{array}$} & Low (up to 31 ) & 23 & 32.9 & \multirow{3}{*}{33.96} \\
\hline & Medium (32-36) & 38 & 54.1 & \\
\hline & High (over 36) & 9 & 12.9 & \\
\hline
\end{tabular}

Note: 1 USD $=80$ BDT

Table 2. Distribution of the respondents according to their attitude towards the use of agro- chemicals in rice cultivation

\begin{tabular}{|c|c|c|c|c|}
\hline Categories & Number & Percentage & Mean & SD \\
\hline A. Less favorable attitude (up to 76) & 6 & 8.5 & & \\
\hline B. Moderately favorable attitude (77-83) & 52 & 74.2 & & \\
\hline C. Highly favorable attitude (over 83) & 12 & 17.3 & 79.73 & 4.48 \\
\hline Total & 70 & 100 & & \\
\hline
\end{tabular}

Note: $\mathrm{A}=$ Low: Mean - 2SD < B $\leq$ Mean - SD; B = Moderate: Mean - SD < C < Mean +SD; C = High: Mean $+\mathrm{SD} \leq \mathrm{D}<$ Mean $+2 \mathrm{SD}$; Range $=63-85$ 
Table 3. Relationship among respondents' characteristics and their attitude towards using agrochemicals in rice field

\begin{tabular}{lllll}
\hline Variables & Coefficient (B) & SE & t-value & p \\
\hline 1. Age & -0.075 & 0.062 & -1.211 & 0.228 \\
2. Educational qualification & 0.258 & 0.290 & 0.892 & 0.374 \\
3. Family size & 0.419 & 0.296 & 1.416 & 0.159 \\
4. Farm Size $^{\text {5. Farmer's Annual income }}{ }^{* *}$ & 0.269 & 5.780 & 0.047 & 0.963 \\
6. Extension media contact $^{* *}$ & -0.081 & 0.023 & -3.581 & 0.000 \\
7. Training received $_{\text {8. Knowledge on use of agrochemical }^{* *}}$ & 1.235 & 0.160 & 7.718 & 0.000 \\
\hline
\end{tabular}

Note: $\mathrm{R}=0.685, \mathrm{R}^{2}=0.469$, Adjusted $\mathrm{R}^{2}=0.439$, Critical Value of $\mathrm{F}=15.590$, and ${ }^{*} \mathrm{p}<0.001$

\section{Conclusions}

More than seventy percent of the farmers had moderately favorable attitude towards the use of agro-chemicals in rice cultivation. This was perhaps because a considerable proportion of the farmers did not have enough training exposure, had moderate use of source of information and extension media contact.

Most of the farmers of the study area were middle aged, had medium family size, all had small farm holding and had primary level of education with an annual income of 55 to 110 thousands BDT (between 1355 USD). Most of them had medium extension contact and medium knowledge on agro-chemical use. All these characteristics had impact on the farmers' attitude towards using agro-chemicals. In addition to this, family annual income, extension media contact and knowledge on agro-chemical use had influence on their attitude towards the use of agro-chemical. Therefore, better annual income, more and more contact with different extension media and good knowledge of using different types of agro-chemicals in rice fields of the respondents influenced them to form more favorable attitude towards using agro-chemicals in rice fields.

Based on the above observations, recommendations may be put forward for further policy formulation. Steps may be taken to impart agro-chemicals, fertilizers and pesticides related training to farmers and effective extension services should be needed for the development and popularization of sustainable agriculture. Mass media, GOs and NGOs may play a vital role in this regard.

\section{References}

Ahmad, M., Arif, M. I. and Ahmad, M. 2007. Occurrence of insecticide resistance in field populations of Spodoptera litura (Lepidoptera: Noctuidae) in Pakistan. Crop Protection, 26: 809-817.

Anonymous. 2015. Average household size by sex of head of household and residence. Bangladesh Bureau of Statistics. Available at: http//bbs.gov.bd/RptHIES_2_1.aspx.

Arcury, T. A., Quandt, S. A., and Russell, G. B. 2002. Pesticide safety among farm workers: perceived risk and perceived control as factors reflecting environmental justice. Environmental Health Perspectives, 110 (2): 233-240.

Chouichom, S. and Yamao, M. 2010. Comparing opinions and attitudes of organic and nonorganic farmers towards organic rice farming system in North-Eastern 
Thailand. Journal of Organic Systems, 5 (1): 25- 35 .

Damalas, C. A. 2009. Understanding benefits and risks of pesticide use. Sci. Res. Essays, 4: 945-949.

Damalas, C. A. and Eleftherohorinos, I. G. 2011. Pesticide exposure, safety issues, and riskassessment indicators. International Journal of Environmental Research and Public Health, 8: 1402-1419.

Delcour, I., Spanoghe, P. and Uyttendaele, M. 2015. Literature review: Impact of climate change on pesticide use. Food Research International, 68: 7-15.

Ghosh, M. K. and Hasan, S. S. 2013. Farmers' Attitude towards Sustainable Agricultural Practices. Bangladesh Research Publications Journal, 8 (4): 227- 235. (Available at: http:// bdresearchpublications.com/admin/journa 1/upload/1308408/1308408.pdf)

Hasan, S. S, Ali, M. A. and Khalil, M. I. 2010. Impact of Pineapple Cultivation on the Increased Income of Pineapple Growers. The Agriculturists, 8 (2): 50-56. (Available at: http://banglajol.info/index.php/AGRIC/art icle/view/7577).

Hasan, S.S., Hossain, M., Sultana, S. and Ghosh, M.K. 2015. Women's Involvement in Income Generating Activities and Their Opinion About Its Contribution: A Study of Gazipur District, Bangladesh. Science Innovation, 3 (6): 72-80.

DOI: $10.11648 /$ j.si.20150306.13

Hasan, S. S., Haque, M. E. and Kabir, T. H. 2005a. Farmers' Attitude towards Integrated Plant Nutrition System for Soil Fertility Improvement. Bangladesh Journal of Training and Development, 18 (1\&2): 45-51.

Hasan, S. S., Haque, M. E., Hasan, M. K., Kabir, T. H. and Talukder, M. S. 2005b. Farmers' knowledge on Integrated Plant Nutrition
System for Increasing Soil Fertility. Journal of Socioeconomic Research and Development, 2 (1): 30-34.

Iqbal, Z., Zia, K. and Ahmad, A. 1997. Pesticide abuse in Pakistan and associated human health and environmental risks. Pakistan Journal of Agricultural Science, 34: 9497.

Isin, S. and Yildirim, I. 2007. Fruit-growers' perceptions on the harmful effects of pesticides and their reflection on practices: the case of Kemalpasa, Turkey. Crop Protection, 26: 917-922.

Khan, M. 2011. Adverse health effects, risk perception and pesticide use behavior. Elixir Journal of Social Science, 38: 4044-4048.

Khan, M., Mahmood, H. Z. and Damalas, C. A. 2015. Pesticide use and risk perceptions among farmers in the cotton belt of Punjab. Pakistan Crop Protection, 67: 184-190.

McCauley, L., Sticker, D., Scherer, J., Lasarev, M., and Michaels, S. 2002. Understanding the pesticide Knowledge and beliefs of adolescent farm workers [Meeting abstract]. Epidemiology, 13: S138-S138.

Pimentel, D. 1995. Pest Management, Food Security, and the Environment: Historyand Current Status. Paper presented at the IFPRI Workshop of the Pest Management, Food Security, and the Environment: the Future to 2020. May1011, 1995, Washington, DC, USA.

Pingali, P. L and Rola, A. C. 1995. Public regulatory roles in developing markets: the case of Philippines. In: Impact of pesticides on farmer health and the rice, (ed.) Pingali, P.L., Roger, P.

Rahman, S. 2010. Six decades of agricultural land use change in Bangladesh: Effects on crop diversity, productivity, food availability and the environment, 19482006. Singapore Journal of Tropical Geography, 31: 254-269. 
Rao, G. V. R., Rameshwar Rao, V., Prasanth, V. P., Khannal, N. P., Yadav, N. K., and Gowda, C.L.L. 2009. Farmers' perception on plant protection in India and Nepal: A case study. International Journal of Tropical Insect Science, 29: 158-168.

Ronald, P. and Adamchak, R. 2010. The future of sustainable food production. Annals of the New York Academy of Sciences, 1190: 184-185.

Salameh, P. R., Baldi, I., Brochard, P. and Abi Saleh, B. 2004. Pesticides in Lebanon: a knowledge, attitude, and practice study. Environmental Research, 94: 1-6.

Salawat, N., Hasan, S. S., Khan, A. S., Rahman, M. S., Hoque, M. M. and Moonmoon, M. 2013. Study on Knowledge and Attitude of Mushroom Growers at Selected Upazilas of Dhaka. Bangladesh Journal of Mushroom, 7 (1): 49-57.

Salazar, M. K., Napolitano, M., Scherer, J. A., and McCauley, L. A. 2004. Hispanic adolescent farm workers' perceptions associated with pesticide exposure including commentary by Smith RAP and Daroszewski EB with author response. Western Journal of Nursing Research, 26: 146-175.
Stadlinger, N., Mmochi, A. J., Dobo, S., Gyllbeack, E. and Kumblad, L. 2011. Pesticide use among smallholder rice farmers in Tanzania. Environment, Development and Sustainability, 13: 641656.

Sultana, B., Zaaba, Z. B. and Umemoto, K. 2010. Women's Empowerment Through the Development of Micro Entrepreneurship in Rural Bangladesh. Social Science, 5: 1-9. DOI: 10.3923/sscience.2010.1.9.

Sultana, S. and Hasan, S. S. 2010. Impact of Micro-Credit on Economic Empowerment of Rural Women. The Agriculturists, 8(2): 43-49. Available at: http//banglajol.info/index.php/AGRIC/arti cle/view/7576.

Tegtmeier, E. M. and Duffy, M. D. 2004. External costs of agricultural production in the United States. International Journal of Agricultural Sustainability, 2: 1-20.

Wilson, C. and Tisdell, C. 2001. Why farmers continue to use pesticides despite environmental, health and sustainability costs? Ecological Economics, 39: 449-62. 